\title{
A.C. Amperometric Method for Lipase Activity Quantification
}

\author{
Roumen Zlatev ${ }^{1, *}$, Margarita Stoytcheva ${ }^{1}$,Zdravka Velkova ${ }^{2}$, Velizar Gochev ${ }^{3}$, Benjamín Valdez, \\ Gisela Montero $^{1}$, Lydia Toscano ${ }^{4}$,Ernesto Beltrán-Partidal, Mario A. Curiel-Álvarez ${ }^{1}$, Mayra C. \\ Ramírez-Camacho ${ }^{1}$ \\ ${ }^{1}$ Universidad Autónoma de Baja California, Instituto de Ingeniería, Blvd. Benito Juárez s/n, 21280 \\ Mexicali B.C., México \\ ${ }^{2}$ Medical University of Plovdiv, Faculty of Pharmacy, 2000 Plovdiv, Bulgaria \\ ${ }^{3}$ University of Plovdiv, Faculty of Microbiology, 2100 Plovdiv, Bulgaria \\ ${ }^{4}$ Instituto Tecnológico de Mexicali, Tecnológico Nacional de México, Mexicali B. C., México \\ *E-mail: roumen@uabc.edu.mx
}

doi: $10.20964 / 2020.12 .12$

Received: 14 April 2020 / Accepted: 6 June 2020 / Published: 31 October 2020

\begin{abstract}
The working electrode modification applying some specific modifiers results in capacitors formation not related to the charges exchange occurring and double layer formation at the electrode - solution interface. Chemical or biochemical processes involving the modification layer cause its thickness variations leading to capacitance changes resulting in AC amperometric response. An AC amperometric method for lipase activity quantification based on this approach was developed and characterized. A thin layer of nanocomposite $\left(\mathrm{SiO}_{2}\right.$ nanoparticles charged olive oil) deposited on the working electrode served as both: sensitive layer toward the lipase and dielectric layer of an electrolytic capacitor formed on the electrode - solution interface. The nanocomposite enzymatic degradation by the lipase causes its thickness decrease proportional to the lipase activity and a corresponding rise of the AC current is registered as analytical response by AC amperometry at fixed small AC amplitude (100 mV p.p.) and frequency of $240 \mathrm{~Hz}$. The developed method was characterized in terms of: LOD, sensitivity, linear quantification range, precision, response time and reproducibility, as well as was validated by spiked samples determination using the standardized titrimetric method as reference.
\end{abstract}

Keywords: AC amperometry, lipases activity quantification, olive oil/ $\mathrm{SiO}_{2}$ nanocomposite

\section{$\underline{\text { FULL TEXT }}$}

(C) 2020 The Authors. Published by ESG (www.electrochemsci.org). This article is an open access article distributed under the terms and conditions of the Creative Commons Attribution license (http://creativecommons.org/licenses/by/4.0/). 